\title{
Ion exchange of layered titanate with transition metal and application to ammonia storage
}

\author{
Kazuki YOKOSAWA ${ }^{1}$, Takahiro TAKEI ${ }^{1, \dagger}$, Sayaka YANAGIDA ${ }^{1}$, \\ Nobuhiro KUMADA ${ }^{1}$ and Ken-ichi KATSUMATA ${ }^{2}$ \\ ${ }^{1}$ Center for Crystal Science and Technology, University of Yamanashi, 7-32 Miyamae, Kofu 400-8511, Japan \\ ${ }^{2}$ Research Institute for Science and Technology, Photocatalysis International Research Center, Tokyo University of Science, \\ 2641 Yamazaki, Noda, Chiba 278-8510, Japan
}

Layered titanates including transition metal in interlayer space were prepared by ion exchange process. Ammonia adsorption was performed into the transition metal-including layered titanates by aqueous liquid and gas phase. X-ray diffraction patterns of the sample with aqueous liquid and gas phase adsorption confirm that ammonia can be adsorbed without collapse of the titanate layered structure. Further, there was a large increase in the ammonia adsorption amount for the sample with gas phase adsorption comparing to that with the aqueous liquid phase adsorption. Such large amount of ammonia adsorption results from the elimination of the water molecules coordinated with the metal cation between the layers by preheating.

(02018 The Ceramic Society of Japan. All rights reserved.

Key-words : Layered titanate, Adsorption, Ammonia

[Received April 7, 2018; Accepted July 4, 2018]

\section{Introduction}

Currently, environment and energy issues are being debated from various viewpoints such as a consumption of fossil fuel, environmental pollution and global warming. ${ }^{1)-3)}$ From now on, new energies that can provide stable supply are required. There are some candidates for energy carrier materials, liquid-phase hydrogen, organic hydride, ammonia, metal magnesium, methanol and so on. ${ }^{4)-6)}$ Among them, ammonia is attracting attention as a reasonable energy carrier. Ammonia has a hydrogen content of approx. 18 mass $\%$ in the molecule containing no carbon, and the burden on the environment can be diminished. In addition, procurement costs can be very low because ammonia can be produced all over the world. Liquid ammonia is relatively easy to prepare and its density is approximately 0.6 to $0.7 \mathrm{~g} / \mathrm{cm}^{3}$ which is 10 times larger than that of liquid hydrogen. These features become large advantages as a hydrogen storage medium. ${ }^{7), 8}$

Ammonia is generally used for wide applications. For example, it is used as a base material for fertilizers, reducing agent, external medicine, coolant etc. ${ }^{9), 10)}$ In recent years, a fuel cell using ammonia as a fuel has been developed. ${ }^{11)}$ Opportunities for use of ammonia will tend to

Corresponding author: T. Takei; E-mail: takei@yamanashi. ac.jp

$\$$ Preface for this article: Dol http://doi.org/10.2109/jcersj2. 126.P10-1 increase in the future. Ammonia can be stored as an aqueous liquid or gas state. However, the solution is necessary to separate into ammonia and water, and the gas has a risk of leakage. Safe storage is necessary for ammonia because it has a stimulative odor, toxic substance, lethal dose ( $30 \mathrm{~mL}$ in $25 \%$ aqueous solution). Therefore, storage of ammonia molecule and reasonable process for ammonia treatment are required.

Lepidocrocite-type layered titanate is a compound having a layered structure. The layers composed of edge shared $\mathrm{TiO}_{6}$ octahedra and alkali metal ions such as $\mathrm{Na}$, $\mathrm{K}, \mathrm{Rb}$ and $\mathrm{Cs}$ are intercalated for charge compensation. A part of the titanium site is vacancy for Cs-type, and is substituted with other mono-, di- or trivalent metal ions for $\mathrm{Na}, \mathrm{K}$ and Rb-types in the interlayer. ${ }^{12), 13)}$ An interlayer cation is generally possible to exchange by a protons and then by other metal cations. The matrix phase has the similar properties as titanium oxide, solid acidity and photocatalytic activity. ${ }^{14)}$

In this paper, we synthesized a lepidocrocite-type layered titanate using $\mathrm{Cs}$ in interlayer space for use as a storage material for ammonia because there are no substitutes in the intralayer position. Various metal cations were introduced between the layers to evaluate the ammonia adsorption characteristics. It is well known fact that some metal cations can form ammine complexes. Therefore, competency and an actual mechanism for adsorption and desorption of ammonia were examined for an application of ammonia storage materials. 


\section{Experimental procedure}

\subsection{Synthesis}

The lepidocrocite-type layered cesium titanate was synthesized by a conventional solid-state process as follows. $\mathrm{Cs}_{2} \mathrm{CO}_{3}$ and $\mathrm{TiO}_{2}$ were mixed wetly and the intimate mixture was placed in an alumina crucible. Then, it was heated at $800^{\circ} \mathrm{C}$ for $1 \mathrm{~h}$ for decarbonation. The mixture was then heated two times at $800^{\circ} \mathrm{C}$ for $20 \mathrm{~h}$ in air. The sample was ground with each cycle. The resultant sample was designated as CTO.

The as-prepared layered titanate was protonated by ionexchange in $\mathrm{HCl}$ aqueous solution as follows. CTO was stirred in $\mathrm{HCl}$ solution (solution/solid $=200 \mathrm{~mL} / \mathrm{g}$ ) at room temperature for 1 week. The $\mathrm{HCl}$ solution with 0.2 , $0.5,0.8$ and $1.0 \mathrm{~mol} / \mathrm{L}$ concentration was used in this process. The solution was replaced by a fresh one everyday to promote the protonation. After that, the protonated sample was separated by centrifugation at $12000 \mathrm{rpm}$ for $5 \mathrm{~min}$, washing several times and drying at $50^{\circ} \mathrm{C}$. The resultant sample was named as HTO.

Layered titanate with intercalation of metal cation was formed by ion exchange. Some sorts of solution were prepared by adding metal acetate or nitrate $(\mathrm{Ca}, \mathrm{Mn}, \mathrm{Co}$, $\mathrm{Ni}, \mathrm{Cu}$ and $\mathrm{Ag}$ ) twice of molar ratio as much as the amount of HTO to ultrapure water of $25 \mathrm{ml}$. HTO was then added to this solution (solution/solid $=250 \mathrm{~mL} / \mathrm{g}$ ) and stirred at $40^{\circ} \mathrm{C}$ for 3 days. After filtration, the samples were washed and dried at $50^{\circ} \mathrm{C}$. These samples were designated as M-HTO (M: Ca, Mn, Co, Ni, Cu or Ag).

\subsection{Ammonia adsorption and desorption}

The layered titanates with metal cation were examined for adsorption of ammonia via an aqueous liquid and a gas phase. In the case of aqueous liquid adsorption, samples were soaked in ammonia aqueous solution (30\% concentration) for 3 days. After soaking, the sample was filtered and dried at room temperature. The obtained samples were designated as M-HTO- $\mathrm{NH}_{3}$ aq. In the case of gas adsorption, samples were heated at $150^{\circ} \mathrm{C}$ for pretreatment by which adsorbed $\mathrm{H}_{2} \mathrm{O}$ molecules on the interlayer cation can be removed. Then, the pretreated samples were kept in pure ammonia gas $(1.0 \mathrm{~L} / \mathrm{g})$ for $16 \mathrm{~h}$. The obtained samples were designated as $\mathrm{M}-\mathrm{HTO}-\mathrm{NH}_{3}$ gas.

Ammonia desorption was characterized by heat treatment. For the heat treatment, the M-HTO-NH${ }_{3}$ aq sample was analyzed by TG-DTA and TG-MASS. For the TGMASS measurement, we paid attention to $\mathrm{m} / \mathrm{z}$ values of 16, 17 and 18 for determination of ammonia desorption temperature. Table 1 shows ammonia and water fragmentation patterns. From the table, ammonia and water can be distinguished by the signal of 16 and 18 of $\mathrm{m} / \mathrm{z}^{15}{ }^{1}$

Table 1. Ammonia and water fragmentation patterns

\begin{tabular}{cccrrrrr}
\hline $\mathrm{m} / \mathrm{z}$ & 14 & 15 & \multicolumn{1}{c}{16} & \multicolumn{1}{c}{17} & \multicolumn{1}{c}{18} & 19 & 20 \\
\hline $\mathrm{NH}_{3}$ & 2.2 & 7.5 & 80.1 & 100.0 & 0.4 & - & - \\
$\mathrm{H}_{2} \mathrm{O}$ & - & - & 0.9 & 21.2 & 100.0 & 0.5 & 0.3 \\
\hline
\end{tabular}

\subsection{Characterization}

Powder X-ray diffraction (XRD) patterns were measured at ambient temperature by $\mathrm{CuK} \alpha$ radiation $(\lambda=$ $1.5418 \AA$ ) with accelerating voltage of $40 \mathrm{kV}$ and tube current of $15 \mathrm{~mA}$ with a scanning rate of $10^{\circ}$ at $2 \theta \mathrm{min}^{-1}$ (MiniFlex600 Rigaku). FT-IR spectra were recorded by Fourier transform infrared spectrometer (FT/IR-4100, JASCO CORPORATION) using KBr method. All samples were measured in transmission mode with the wave number of $400-4000 \mathrm{~cm}^{-1}$. The particle shape and chemical composition were observed by FE-SEM (JSM-6500F, Hitachi). The Amount of ammonia was measured using CHN Coder (MT-5, Yanaco). In the measurements, pnitroaniline was used as standard sample. The TG-MASS measurements were taken at the range from room temperature to $1000^{\circ} \mathrm{C}$ with the rate of $10^{\circ} \mathrm{C} \mathrm{min}^{-1}$ in flowing $\mathrm{He}$ (Thermo-MASS, Rigaku).

\section{Results and discussion}

\subsection{Preparation of cation exchanged layered titanate}

Figure 1 shows XRD patterns of CTO and HTO treated by various concentrations of $\mathrm{HCl}$ as a protonation agent. The diffraction peak $(020)$ at around $10^{\circ}$ in $2 \theta$, which indicates interlayer spacing, is quite small in CTO because intercalated $\mathrm{Cs}$ cation has relatively large atomic mass. The chemical formula of CTO was determined to $\mathrm{Cs}_{0.70} \mathrm{Ti}_{1.825} \mathrm{O}_{4}$. By protonation, intensity of the peak increases steeply due to drastic decrease of electronic density between layers for the sample by 0.2 and $0.5 \mathrm{M} \mathrm{HCl}$. This phenomenon can be regarded as a collateral evidence for replacement of $\mathrm{Cs}$ cation by proton. However, the diffraction peaks become broad on further higher concentrations of $\mathrm{HCl}$. These patterns confirm anatase emergence. Actually, the protonation degree of each samples are $75,97,98$ and $91 \%$ for $0.2,0.5,0.8$ and $1.0 \mathrm{M}$, respectively. Therefore, optimal concentration of $\mathrm{HCl}$ seems to be $0.5 \mathrm{M}$.

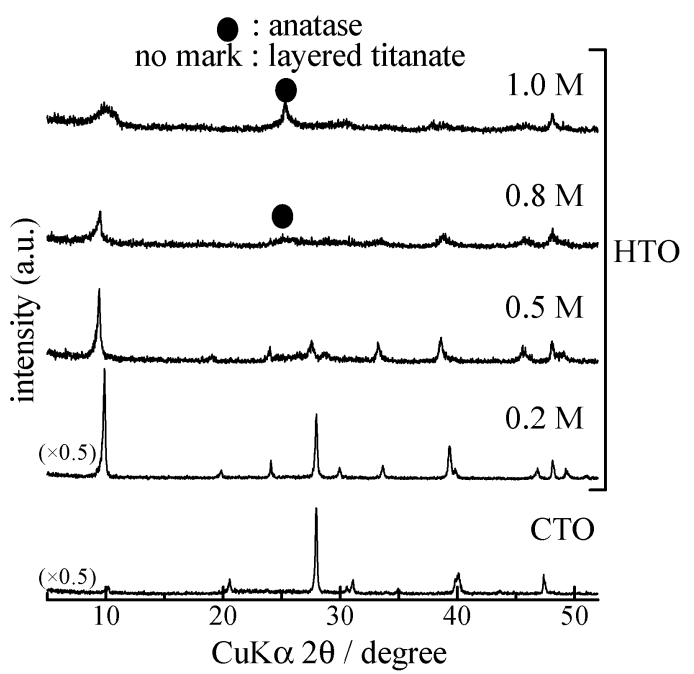

Fig. 1. XRD patterns of CTO and HTO protonated by various concentration of $\mathrm{HCl}$. 


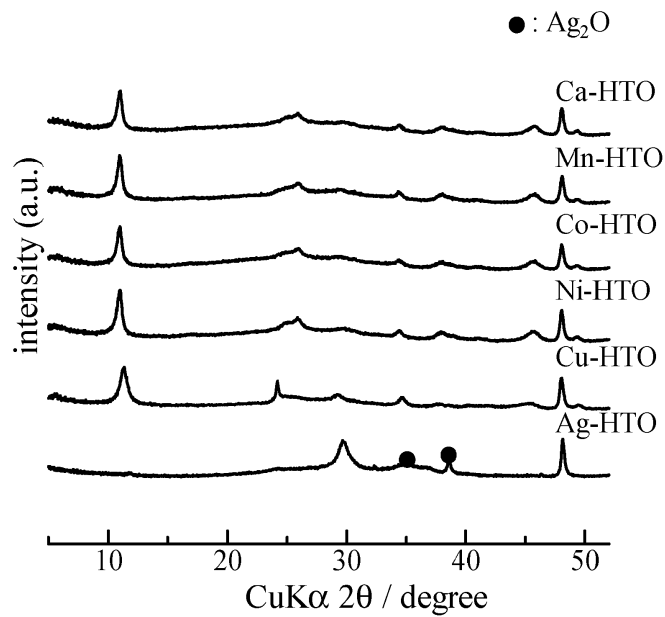

Fig. 2. XRD patterns of ion exchanged samples using metal nitrates.

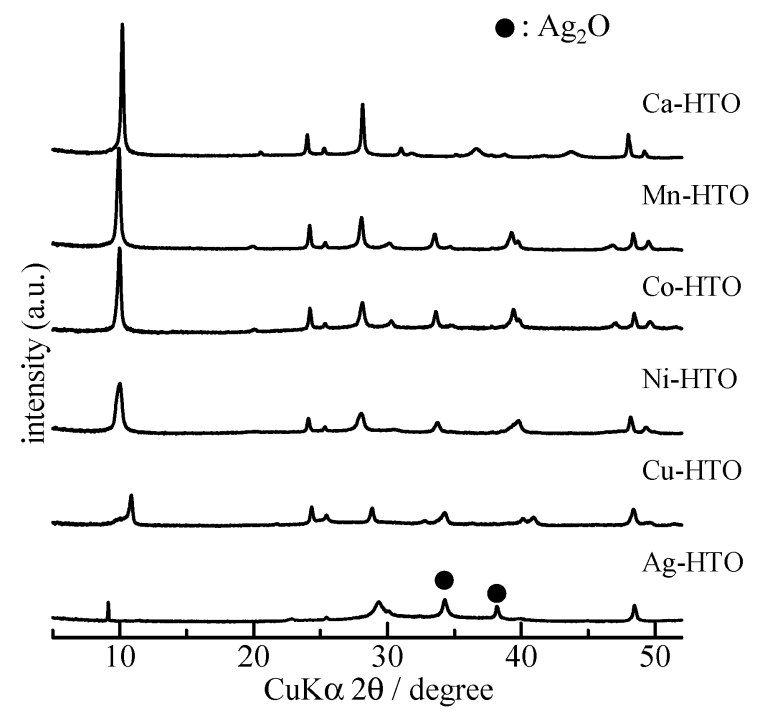

Fig. 3. XRD patterns of ion exchanged samples using metal acetates.

Figure 2 shows the XRD patterns of the ion exchanged samples using metal nitrates. Except for Ag-HTO, these samples show diffraction peaks $(020)$ at around $10^{\circ}$ indicating interlayer spacing of the lepidocrocite-type structure. Consequently, metal cations could be introduced between the layers while maintaining the layered structure. However, the diffraction peaks seem to broaden and the crystallinity declines. For Ag-HTO sample, diffraction peaks of $\mathrm{Ag}_{2} \mathrm{O}$ emerge and a peak at around $10^{\circ}$ disappears. Figure 3 shows the XRD patterns of the ion exchanged samples using metal acetates. In the patterns of all samples, a diffraction peak (020) at around $10^{\circ}$ indicating interlayer spacing was observed. The intensity ratio of the diffraction peak was changed by introducing various cations between the layers. This change is assumed to be due to a change of partial electron density and lattice constant by the introduced cation species between the layers. For $\mathrm{Ag}-\mathrm{HTO}, \mathrm{Ag}_{2} \mathrm{O}$ emerges in the XRD pattern. A monovalent cation might be difficult to be included into
Table 2. Amount of ion exchanged cation by metal nitrate and acetate

\begin{tabular}{ccc}
\hline cation & Metal nitrate/\% & Metal acetate $/ \%$ \\
\hline $\mathrm{Ca}^{2+}$ & 5 & 54 \\
$\mathrm{Mn}^{2+}$ & 9 & 86 \\
$\mathrm{Co}^{2+}$ & 10 & 76 \\
$\mathrm{Ni}^{2+}$ & 4 & 73 \\
$\mathrm{Cu}^{2+}$ & 20 & 77 \\
$\mathrm{Ag}^{+}$ & 56 & 100 \\
\hline
\end{tabular}

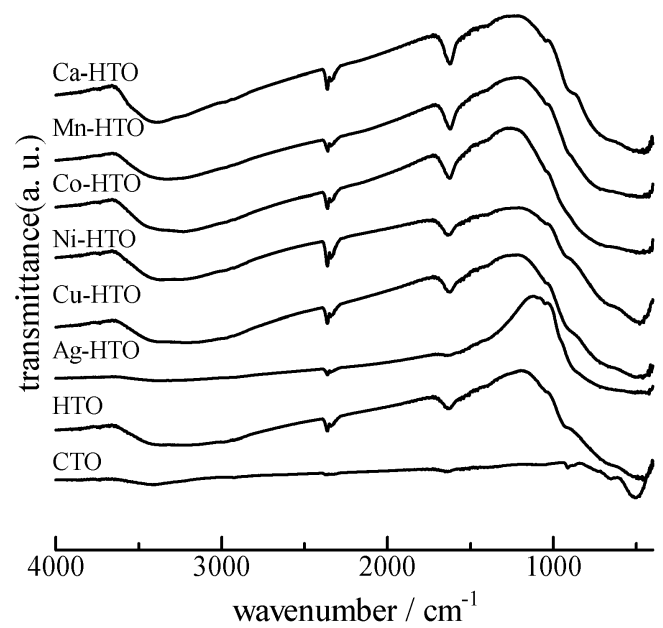

Fig. 4. FT-IR spectra of the ion exchanged samples using metal nitrates.

the interlayer again. These XRD patterns show narrower diffraction lines than those of samples using metal nitrates. As a metal acetate is one of the salt of a weak acid, the layered titanate receives less damages than those by metal nitrate.

Table 2 shows amounts of ion exchanged cation using metal nitrate or acetate. In the case of metal nitrate, all samples except Ag-HTO shows small amounts about 20\% or less. On the other hand, excluding the Ca-HTO, the amount shows a higher value of $70 \%$ or more for the samples using metal acetate. In the Ag sample, the reason for the large amount results from the formation of $\mathrm{Ag}_{2} \mathrm{O}$. The reason for the large amounts of cations by metal acetates will be difference between acid dissociation constants. The acid dissociation constants of nitric acids are higher than those of acetic acids. In other word, nitric acids tend to be dissociated more in aqueous solution. The equilibrium proceeds to the opposite side of dissociation by increasing proton for metal acetate. In the case of metal nitrates, the dissociated nitrate ion is difficult to consume the proton because nitric acids are strong. Consequently, metal acetate salts provide larger amounts of metal cations introduced. From the above results, we use a sample by metal acetates hereafter.

Figure 4 shows the FT-IR spectra of the ion exchanged samples using metal acetates. The peaks at around 3500 $\mathrm{cm}^{-1}$ and at around $1600 \mathrm{~cm}^{-1}$ are attributed to stretching and deformation vibration of $\mathrm{H}_{2} \mathrm{O}$ in $\mathrm{KBr}$, respectively. The peak at around $2400 \mathrm{~cm}^{-1}$ is antisymmetric stretching 
vibration of $\mathrm{C}=\mathrm{O}$ in $\mathrm{CO}_{2}$ in the atmosphere. At smaller than $1000 \mathrm{~cm}^{-1}$ range which is called a fingerprint region, Ti-O vibration can be observed.

\subsection{Adsorption of Ammonia}

Figure 5 shows the XRD patterns of the sample with ammonia adsorption via a liquid phase. The samples except for the Ag-HTO show slightly shift of the diffraction peak (020). Such shifts will result from formation of an ammonia complex with interlayer cations. On the other hand, Ag-HTO shows low crystallinity since the diffraction peak broadened and the diffraction peak (020) indicating the interlayer spacing could not be confirmed. Figure 6 shows the FT-IR spectra of the sample with ammonia adsorption via an aqueous liquid phase. The peak at around $1300 \mathrm{~cm}^{-1}$ emerges by ammonia adsorption. This peak is derived from symmetric deformation vibration of $\mathrm{N}-\mathrm{H}$ in an ammonia molecule. These spectra confirm ammonia adsorption to the cation-intercalated layered titanates.

The amount of ammonia by an aqueous liquid phase was measured by $\mathrm{CHN}$ coder. The amounts were around

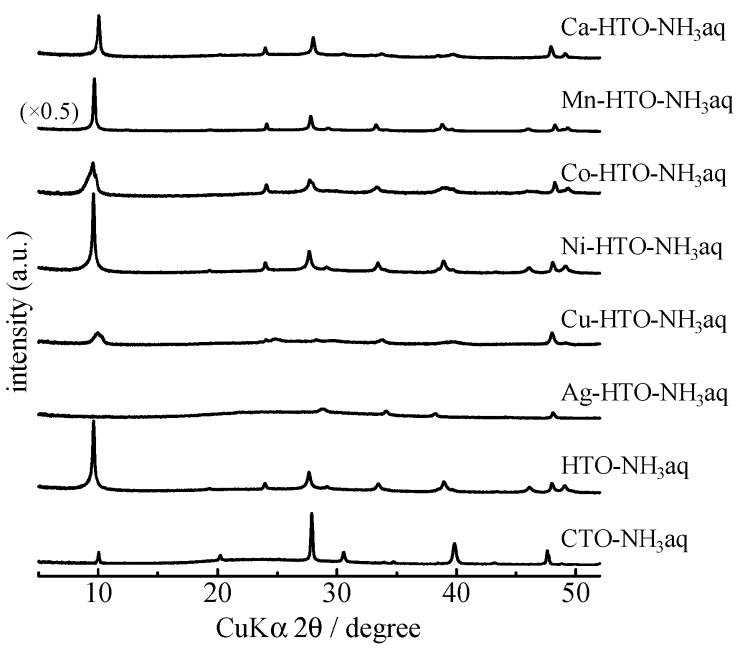

Fig. 5. XRD patterns of the sample with ammonia adsorption via aqueous liquid phase.

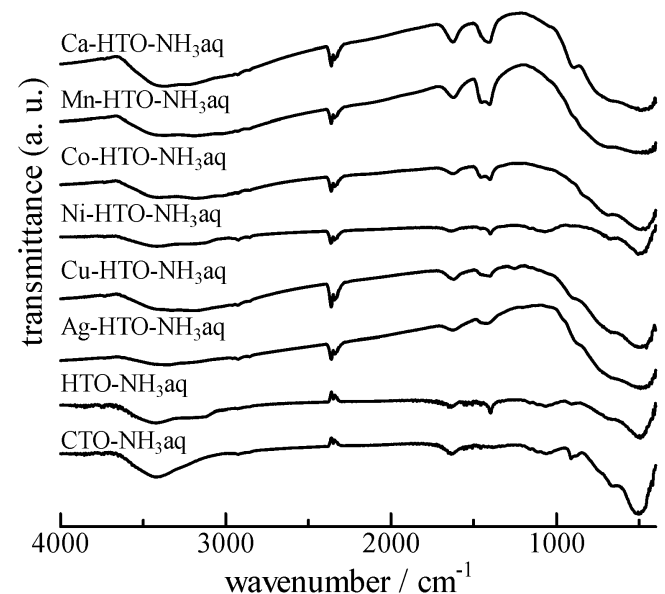

Fig. 6. FT-IR spectra of the sample with ammonia adsorption via aqueous liquid phase.
1.5-3.8 mass \% for M-HTO, and 4.3 mass $\%$ for HTO. The plausible reason of the small amount of ammonia in the M-HTO samples is water coordination to metal cations in interlayer instead of ammonia. The ratio of adsorbed ammonia on exchanged cation can be calculated to around $0.4-1.6$. In general, $\mathrm{Mn}^{2+}, \mathrm{Co}^{2+}$ and $\mathrm{Ni}^{2+}$ have six, $\mathrm{Cu}^{2+}$ has four and $\mathrm{Ag}^{+}$has two ammonia ligands in the ammine complex. ${ }^{16)}$ For $\mathrm{Ca}^{2+}$, although there are few literatures for an ammine complex, a plausible value is eight ammonia ligands because of formation of $\mathrm{CaCl}_{2} \cdot 8 \mathrm{NH}_{3} .{ }^{17)}$ The actual values in this paper are much lower than the theoretical ratio. In other words, there are some possibilities for increasing ammonia adsorption.

In the case of protonated sample, $\mathrm{HTO}-\mathrm{NH}_{3} \mathrm{aq}$, a proton can be coordinated to an ammonia molecule to form an ammonium ion. According to the ratio of proton to ammonia is $1: 1$ in the ammonium ion, $64 \%$ of the proton was used for adsorption of ammonia. On the other hand, for example, the Ni-HTO sample shows only about $26 \%$ of the adsorption limit in the aqueous ammonia solution.

Figure 7 shows the temperature dependence of amount of fragmentation species with $\mathrm{m} / \mathrm{z}=16,17$ and 18 for Co-HTO-NH ${ }_{3}$ aq. From the TG-MASS, the peaks at $80^{\circ} \mathrm{C}$ were observed in the curve of $\mathrm{m} / \mathrm{z}=17$ and 18 , and the peaks at around $230^{\circ} \mathrm{C}$ were observed in the curve of $\mathrm{m} / \mathrm{z}=16$ and 17 . Generally, $\mathrm{NH}_{3}$ species must be detected in the curve of $\mathrm{m} / \mathrm{z}=16$ and 17 at an intensity ratio of approximately 4:5 while $\mathrm{H}_{2} \mathrm{O}$ should show an intensity ratio of approximately $1: 5$ for $\mathrm{m} / \mathrm{z}=17$ and 18 as showed in Table 1. Thus, the peak in $\mathrm{m} / \mathrm{z}=18$ means $\mathrm{H}_{2} \mathrm{O}$, and that in $\mathrm{m} / \mathrm{z}=16$ indicates $\mathrm{NH}_{3}$ existence. In the curve of $\mathrm{m} / \mathrm{z}=17$, both $\mathrm{H}_{2} \mathrm{O}$ and $\mathrm{NH}_{3}$ can be detected as a peak. Therefore, from the TG-MASS curve, $\mathrm{H}_{2} \mathrm{O}$ will be desorbed at around $80^{\circ} \mathrm{C}$ and $\mathrm{NH}_{3}$ at around $230^{\circ} \mathrm{C}$, respectively. From these curves, intensity ratio of $\mathrm{NH}_{3}$ $(\mathrm{m} / \mathrm{z}=16) / \mathrm{H}_{2} \mathrm{O}(\mathrm{m} / \mathrm{z}=18)$ peaks can be calculated to around 0.31 . Therefore, the amount of coordinated $\mathrm{NH}_{3}$ may be smaller than $\mathrm{H}_{2} \mathrm{O}$. For the desorption temperature, the adsorbed ammonia in zeolite which has strong solid acidity have been reported at $400-700^{\circ} \mathrm{C} .{ }^{18)}$ Our samples showed a relatively low temperature of about $230^{\circ} \mathrm{C}$. Such

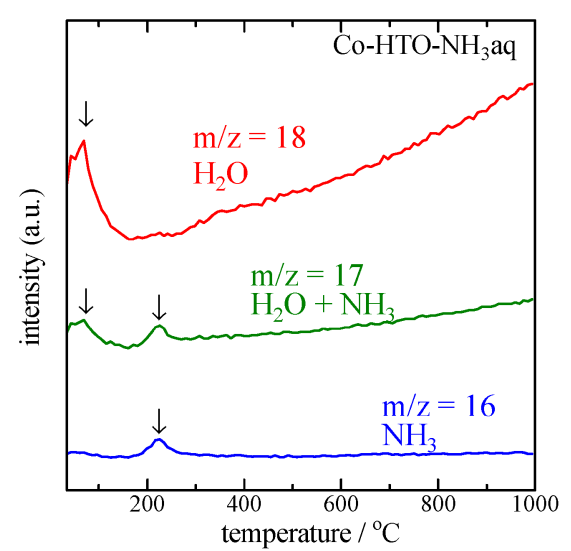

Fig. 7. Temperature dependence of amount of fragmentation species with $\mathrm{m} / \mathrm{z}=16,17$ and 18 for $\mathrm{Co}-\mathrm{HTO}-\mathrm{NH}_{3}$ aq samples. 


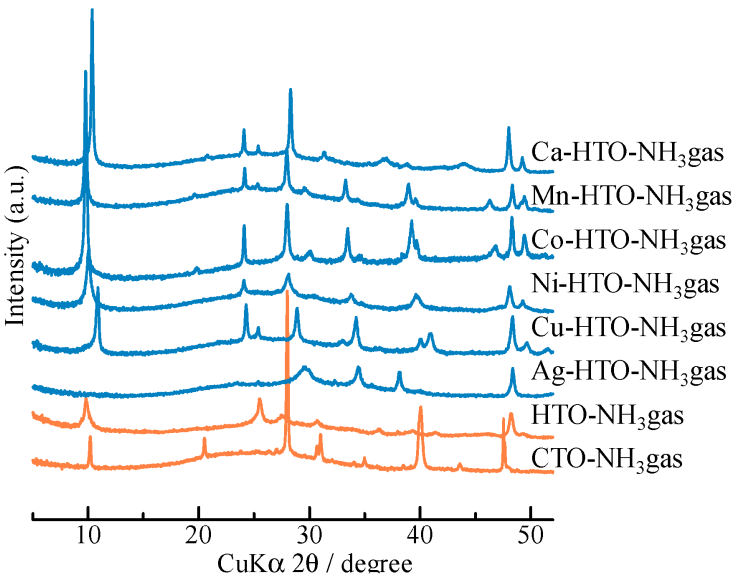

Fig. 8. XRD patterns of MTO sample with ammonia adsorption via gas phase.

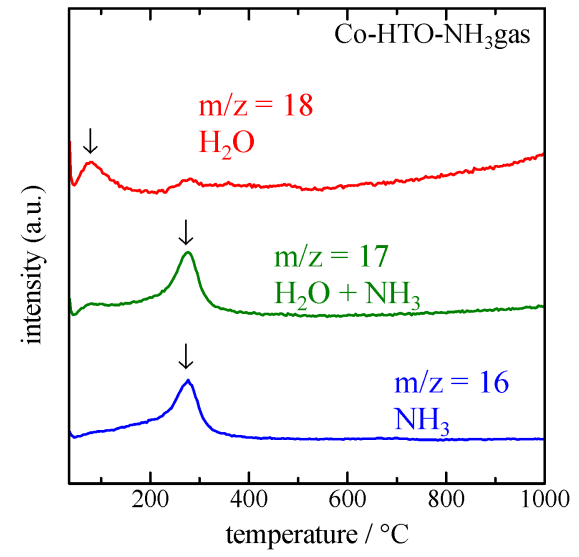

Fig. 9. Temperature dependence of amount of fragmentation species with $\mathrm{m} / \mathrm{z}=16,17$ and 18 for $\mathrm{Co}-\mathrm{HTO}-\mathrm{NH}_{3}$ gas samples.

low desorption temperature is achieved by adsorption of ammonia by forming an ammine complex with metal cations between layers, and possibly becomes a strong advantage for use of ammonia storage application.

In order to increase the amount of adsorption of ammonia, gas phase adsorption of ammonia was examined. Figure 8 shows the XRD patterns for M-HTO sample with adsorption of ammonia by gas phase. There XRD patterns confirm that the diffraction peak of the interlayer spacing in a gas phase adsorption were slightly narrower than those by liquid phase adsorption. However, similar to the liquid phase adsorption, the (020) plane showing the layer structure in the Ag sample could not be observed. From this result, the sample except for the Ag-included one can adsorb ammonia while maintaining the layer structure.

Figure 9 shows the temperature dependence of amount of fragmentation species with $\mathrm{m} / \mathrm{z}=16,17$ and 18 for CoHTO- $\mathrm{NH}_{3}$ gas. From this curve, intensity of the $\mathrm{H}_{2} \mathrm{O}$ peak with $\mathrm{m} / \mathrm{z}=18$ at $80^{\circ} \mathrm{C}$ decreased apparently. For $\mathrm{NH}_{3}$, the peak $(\mathrm{m} / \mathrm{z}=17$ and 18$)$ shifted slightly to approx. $270^{\circ} \mathrm{C}$. The intensity ratio for these peaks, $\mathrm{NH}_{3} / \mathrm{H}_{2} \mathrm{O}$ increased drastically to around 2.25 . From these results, gas adsorp-

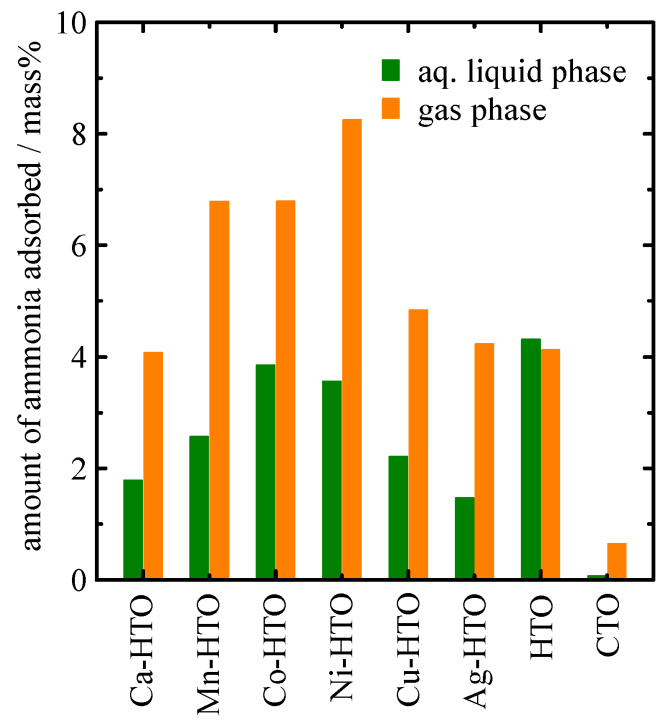

Fig. 10. Amounts of ammonia by aqueous liquid and gas phase.

tion is much effective than that in the aqueous solution for increase of adsorption amounts.

Figure 10 shows amounts of ammonia by liquid and gas phase. For HTO, the amounts of ammonia adsorption are similar for the samples by gas and liquid adsorption processes. However, M-HTO samples show two times better competency for adsorption of ammonia by gas phase than that by aqueous liquid phase. The reason of such increase of the amount of ammonia adsorption may be removal of water molecules coordinated to the metal cations between the layers by pretreatment. Consequently, M-HTO can adsorb more than 8 mass \% of ammonia maximally using Ni-HTO. From the literatures, around 10 mass \% of ammonia can be adsorbed reversibly. ${ }^{19), 20)}$ Our materials show slightly smaller adsorption amount than the zeolites. However, exchange degree of Ni-HTO was only $73 \%$ as shown in Table 2 . In addition, ammonia did not adsorb fully on $\mathrm{Ni}^{2+}$ for coordination number, 6 . Actual mean coordination number can be estimated as around 4.8. Therefore, our material might have more competence for adsorption of ammonia. If $\mathrm{Ni}$ cation exchanges completely and ammonia can coordinate fully, the adsorption amount will be around 14 mass \%. Thus, our material can be regarded as a potential candidate for ammonia adsorbing materials.

\section{Conclusions}

Lepidocrocite-type layered titanate was prepared by conventional solid-state reaction, and its protonation was carried out by introducing the lepidocrocite type layered titanate into $0.5 \mathrm{M}$ hydrochloric acid. The protonation was accomplished with exchange degree of $97 \%$.

Metal cations, $\mathrm{Ca}, \mathrm{Mn}, \mathrm{Co}, \mathrm{Ni}, \mathrm{Cu}$ and $\mathrm{Ag}$, can be introduced into the interlayer gallery with ion exchange degree of $70 \%$ or larger using metal acetate. In the case of metal nitrate, ion exchange degree was $20 \%$ or less. Weaker acid salt will tend to be introduced into the interlayer space. 
For the cation exchanged samples except for the AgHTO, the layered structure could be maintained after adsorption of ammonia. However, the composition ratio of metal cations and ammonia was apparently lower than the ideal ratio. The reason is plausibly due to the fact that water coordination reduces space for coordination of ammonia.

Adsorbed $\mathrm{H}_{2} \mathrm{O}$ and $\mathrm{NH}_{3}$ tend to desorb from the sample at around $80^{\circ} \mathrm{C}$ and $230-270^{\circ} \mathrm{C}$. This result may be due to the adsorption of ammonia by forming an ammine complex with metal cations between layers. Such lower desorption temperature of ammonia can be strong advantage of the application. For example, these materials can be suggested to separate $\mathrm{NH}_{3}$ from ammonia water (ammonia purification) by adsorption in aqueous solution and desorption by heating at $230-270^{\circ} \mathrm{C}$.

The gas adsorption of ammonia was carried out and showed two times as much as the ammonia amounts of liquid phase adsorption. This result indicates that amount of ammonia can be possible to increase by removing water coordinated to cations between layer and adsorbing in a gas phase.

Acknowledgement A part of this research was supported by Joint Usage/Reserch Center in Tokyo University of Science, and by Grand-in-Aid for Scientific Research (C) 16K06720.

\section{References}

1) K. T. Sanders, Environ. Sci. Technol., 29, 51-66 (2015).

2) M. Günther and T. Hellmann, J. Environ. Econ. Manag., 81, 38-58 (2017).

3) E. von Schneidemesser, P. S. Monks, J. D. Allan, L. Bruhwiler, P. Forester, D. Fowler, A. Lauer, W. T. Morgan, P. Paasnen, M. Righi, K. Sindelarova and M. A. Sutton, Chem. Rev., 115, 3856-3897 (2015).

4) R. W. P. Wagemans, J. H. van Lenthe, P. E. de Jongh,
A. J. van Dillen and K. P. de Jong, J. Am. Chem. Soc., 127, 16675-16680 (2005).

5) F. Alhumaidan, D. Cresswell and A. Garforth, Energ. Fuel., 25, 4217-4234 (2011).

6) W. Luo, P. G. Campbell, L. N. Zakkarov and S. Y. Liu, J. Am. Chem. Soc., 133, 19326-19329 (2011).

7) S. Giddey, S. P. S. Badwal, C. Munnings and M. Dolan, ACS Sustain. Chem. Eng., 5, 10231-10239 (2017).

8) T. Zhang, H. Miyaoka, H. Miyaoka, T. Ichikawa and Y. Kojima, ACS Appl. Energy Mater., 1, 232-242 (2018).

9) A. L. Strauss, C. L. Reardon and M. Mazzla, Soil Biol. Biochem., 68, 410-418 (2014).

10) A. M. Adham, N. Mohd-Ghazali and R. Ahmad, Proc. Eng., 56, 337-343 (2013).

11) J. Yang, A. F. S. Molouk, T. Okanishi, H. Muroyama, T. Matsui and K. Eguchi, ACS Appl. Mater. Interfaces, 7 , 7406-7412 (2015).

12) T. Sasaki, M. Watanabe, Y. Michiue, Y. Komatsu, F. Izumi and S. Takenouchi, Chem. Mater., 7, 1001-1007 (1995).

13) T. Gao, H. Fjellvag and P. Norby, Chem. Mater., 21, 3503-3513 (2009).

14) T. A. Stewart, M. Nyman and M. P. deBoer, Appl. Catal. B-Environ., 105, 69-76 (2011).

15) NIST Chemistry WebBook NIST Standard Reference Database Number 69, https://webbook.nist.gov/ chemistry/.

16) R. H. Crabtree, "The Organometallic Chemistry of the Transition Metals", Wiley-Interscience, New Jersey (2005) pp. 1-51.

17) V. E. Sharonov, J. V. Veselovskaya and Y. I. Aristov, Int. J. Low-Carbon Technol., 1, 191-200 (2006).

18) L.-E. Sandoval-Díaz, J.-A. González-Amaya and C.-A. Trujillo, Micropor. Mesopor. Mat., 215, 229-243 (2015).

19) C. Y. Liu and K. Aika, J. Jpn. Petrol. Inst., 46, 301-307 (2003).

20) T. Miyoshi, K. Boki and S. Tanada, Jpn. J. Ind. Heath, 19, 87-91 (1977). 